\title{
Organic farmer takes gene battle to court
}

[LONDON] A dispute over the distance pollen can travel while remaining able to crosspollinate effectively with other plants has become the latest twist in the British debate about genetically modified crops.

The issue is central to a court challenge being mounted by a farmer who is trying to stop an experimental crop of genetically modified maize being planted next to his farm in Devon. The farmer, Guy Watson, is being supported by the environmentalist group Friends of the Earth and by the Soil Association, Britain's largest certifier of organic produce.

The three have joined forces out of concern that the maize, which has been modified to be resistant to a herbicide, may pollinate a field of organic sweetcorn planted two kilometres away on Watson's farm. The Soil Association says it will withdraw Watson's 'organic' certificate if the trial goes ahead.

But Sharpes International Seeds Limited, the company responsible for the trials, argues that the farmer and his supporters are unduly concerned. Along with the National Institute of Agricultural Botany in Cambridge - which is conducting the trial on Sharpes' behalf - the company contends that the likelihood of pollen from the modified field contaminating the organic sweetcorn is too small to be measured.

This, they say, is because the distance between the two fields is 10 times the minimum legal requirement to achieve the 99.9 per cent seed purity that a crop needs for organic certification.

The court case is the latest hurdle to attempts to commercialize genetically modified crops in Britain, in the wake of mounting public concern about their safety.

Some local authorities are refusing to serve genetically modified food in school meals, and some supermarket chains will not stock unlabelled genetically modified products imported from the United States.

Conservation groups are advocating a complete moratorium on commercialization until important questions can be answered. Last month Prince Charles expressed deeply held beliefs against the genetic manipulation of food.

The resistance to genetic modification of crops is not just passive. Experimental crop sites are frequently vandalized, leading to producers calling on the government not to make their location public on the grounds that they are being prevented from carrying out research that will help to establish whether genetically modified crops are safe or not (see Nature 393, 726; 1998).

The government has found itself torn between those who want to push ahead with commercial-scale crops and those who want to tread a more cautious line. The Depart-

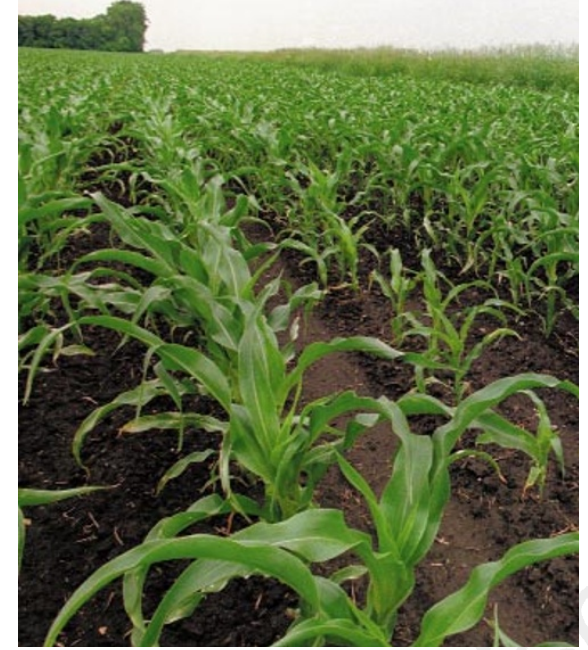

until the minister issues his formal response.

The views of ACRE members are well known to those following the debate, which is why Friends of the Earth, the Soil Association and Watson chose to go to court before Meacher's formal response. They also want the trial to be halted before the flowering season begins this month, which is when pollination will take place.

Pete Riley, a biotechnology campaigner for Friends of the Earth, says the evidence for cross-pollination is overwhelming. He says that pollen can maintain its fertilizing ability for up to 80 hours after flowering.

In addition, Riley says that recent laboratory research points to a higher mortality rate among lacewings that feed on genetically modified maize, apparently contradicting an earlier field study. He also questions the overall desirability of a crop that has been genetically modified to be resistant to herbicide when research has shown that such a crop can transfer herbicide resistance to weeds growing nearby.

Scientists generally agree that some pollen can be long-lived, and that it can also travel distances of up to a kilometre.

But one of the main scientific difficulties in this issue is that the probability of crosspollination, and its effects on the environment and food safety, is too small to be studied effectively. This, says Mick Crawley of Imperial College, London, is one of the biggest obstacles to further research.

What is known, says one ACRE member, is that the "vast majority" of pollen grains lose their fertilizing ability within half an hour, and do not travel distances much beyond 200 metres. Experience, he says, shows that a distance of 200 metres between two crops results in 99.9 per cent seed purity. "This limit is an internationally agreed standard based on practical experience. It has not been set by people sitting in an office."

For cross-pollination to occur, he adds, the two crops must flower at the same time, which he believes is unlikely. The sweetcorn must also be located downwind of the maize.

The Devon site contains six plots of modified maize, with some 1,200 plots of unmodified crops. The ACRE member says that the likelihood of cross-pollination from these unmodified sources is more likely than from one of the genetically modified sites.

On the issue of herbicide tolerance spreading to other plants, the ACRE member says that such a trait tends to appear "within a few generations" of a single crop which is constantly sprayed with herbicide.

"The trouble with the opposition to genetic modification is that it is rooted in too much Plato, and not enough Aristotle", he says. "There is not enough of the detail, and too much of the general."
EhsanMasood 